diphtheria toxoid. In such individuals any one of the diphtheria antigens-toxoid, A.P.T., or T.A.F.-given in the usual dosage will elicit reactions of varying degrees of severity. Large-scale immunization of an adult population, or of older school-children, should therefore not be undertaken without preliminary Schick-testing. Pseudo-reactors are preferably not given any injections, as, being already partially immune, they are unlikely to develop diphtheria, and indeed the Schick test material itself is often sufficient to render them negative to further tests. If, however, preliminary Schick-testing cannot be done, the safest prophylactic for adults is T.A.F. An initial dose of $0.2 \mathrm{c} . \mathrm{cm}$. should be given to all volunteers, and nonreactors should receive two further doses of $1 \mathrm{c.cm}$. at three to four week intervals. Reactors should not be given any further injections.

\section{Senile Pruritus}

Q.-Is complete rest in bed likely to prove beneficial to an intractable case of senile pruritus in a patient aged 80 ?

A.-Senile pruritus is unlikely to benefit from rest in bed, and might even be made worse, because the patient is able to give more attention to the itching skin.

\section{Clicking Joints in a Baby}

Q.-A mother states that she can hear the joints of the back cracking in her 14-months child. I have been unable to find any abnormality. Should I refer the case to an orthopaedic surgeon?

A.- The present writer in an extensive orthopaedic practice has seen a few small infants who have had queer clicking joints. The phenomenon appears to be without any great significance, for these symptoms seem to disappear. Unless there is any clear evidence of physical disturbance one would suggest leaving the problem and reviewing it from time to time. If the mother continues to be distressed by the peculiarities which the child presents it would certainly be worth while seeking confirmatory advice.

\section{INCOME TAX}

\section{Assistant Provided with Furnished House}

S. B. employs two assistants, each of whom has the use of a free furnished house; he pays income tax on the rental value and also owners' and tenants' rates.

${ }_{*}^{*}$ S. B. can deduct as an expense of the practice the amounts on which he bears income tax in respect of the properties-as he could deduct the rent if he rented them. He can also deduct the payments he makes for repairs, rates, maintenance of furniture, insurance, and other current expenses incurred on the properties.

\section{Appointment : Travelling Expenses}

I. W. is a medical officer whose duties involve a good deal of travelling. As he is compelled to live out he receives an allowance of $£ 100$ per annum. When he goes away he receives a subsistence allowance of 14s. a day for the first 7 days and 9s. a day for succeeding days. These rates, it is suggested, are too low, as they compare unfavourably with the 20 s. a day which would be paid as subsistence if he were living in a hospital. Can he claim anything for income-tax purposes in view of his low subsistence rates?

${ }_{*}^{*}$ The governing principle is that a claim can be made only for expenses incurred "wholly, exclusively, and necessarily in the performance of the duties of the office." What I. W. would have to do to succeed in his claim would be to satisfy the local inspector of taxes (or on appeal from his decision a board of commissioners) that the cost of his visits outside his residential radius was necessarily greater than the amounts allowed him by his employer; and in measuring that cost it is to be presumed that any savings in respect of food, etc., at his residence would be taken into account. Obviously his prospects of success depend on his particular circumstances, but proof of the correctness of his claim would be difficult.

\section{Fluctuation in Income}

E. T. first became liable to income tax for 1944-5, but since April, 1945 , owing to illness, has earned only $£ 16$. Can the two years be combined or averaged?

${ }_{*}^{*}$ No; each financial year must be treated as an isolated unit.

\section{Appointment : Car Expense}

H. S. had retired and subsequently accepted an appointment involving attendance at a board held 12 miles distant from his residence. Can he claim to deduct the expense of travelling to and from the board?

** No. In the circumstances the expense is incurred not " in performing the duties of the office" but antecedently in order that H. S. may be in a position to commence performing his duties. The case is somewhat similar to that of an employee who lives in the suburbs and travels to his employment.

\section{LETTERS, NOTES, ETC. Medical Books for Yugoslavia}

Mr. Harold Edwards (King's College Hospital, Denmark Hill S.E.5) writes: The doctors of Yugoslavia are very short of moder British medical literature, having received practically none since the war started. They are most anxious to make good this shortage, and on a recent visit to Belgrade I promised those who asked me $\Rightarrow$ and they were many-to do what I could to help. If any of your readers can spare any standard works or series of periodicals (odd ones or twos are of little value) published in the Uaited Kingdof since September, 1939, and would send them to me I wiil undertake to have them forwarded to Yugoslavia through military channels kind agreement of the D.G.A.M.S., Sir Alexander Hood. A gigt of this kind would be appreciated very much, and may help to increase the friendship and good will between the two countries. It is suggested that contributors write inside each volume: "The gift of (name and address)." This may lead to the development of individual friendships.

\section{Coccygodynia}

Dr. T. Astley COOPER (Birmingham) writes: I wonder if a@y other practitioner has had similar experience to mine. I have had deal lateiy with a rather interesting case of coccygodynia. The man is about 40 years of age and complains that from time to time he awakes during the night with a vague sensation of discomfort the region of the sacrum. This discomfort gradually develops inde a most intense neuralgic pain in the region of the coccyx. Nothing will relieve the pain until, after pacing the bedroom for some tims, a small amount of flatus is passed. The pain then subsides, but os so severe at the time that it leaves him quite exhausted. Another interesting feature is that it will frequently occur after sexual intelcourse. Physical examination is quite negative and there is nothigु to be discovered per rectum. These attacks have occurred at intovals since childhood. The only information I can get is that it coccygodynia-which is obvious; but no help as to the possige cause of this pain or suggestions regarding its prevention. I presume it is due to pressure, but what the mechanism of this is remanes rather a mystery.

\section{Abortion and the Birth Rate}

Dr. B. Dunlop (Binfield, Berks) writes: Your welcome artice (Dec. 29, p. 926) about the book Britain and her Birth-rate conta角s a long quotation from it which asks: "Is the sad truth to-day th children are distributed in inverse ratio to knowledge and the abiliky and desire to assimilate facts?"; and which later says: "There?s no reason to suppose that legislation will alter this pattern fundamentally." I submit that legislation could, however, alter th pattern fundamentally by relaxing the abortion law sufficiently fo $_{3}$ enable women to avoid having more children than they desire $-{ }_{a}$ law which is an outstanding infringement on liberty.

\section{Hospital Service Plan}

Dr. S. M. R. Thomson (London, E.13) writes: The letter by sir Hugh Lett and Dr. W. Russell Brain on the London Hospital Servee Plan (Dec. 29, p. 936) brings to the notice of the medical profession a very useful scheme. While it is a good plan for the genea 1 public, I would recommend it also to doctors and their dependanits. The fees for hospital and for medical and surgical in-patient treasment are paid direct to the hospital and to the surgeon or physicizin who has given the necessary treatment. If a doctor or his dependagt has been the patient this simplifies the question of gifts for servige rendered and puts the whole matter on a business-like basis, maxe satisfactory to all concerned.

\section{Nylon for Buried Sutures}

Dr. T. Russell Stevens (Dorchester) writes: May I assure i H. A. Haxton (Jan. 12, p. 66) that I will try his method of tyde knots with nylon. Our case for nylon is strengthened by the two letters by $\mathrm{Mr}$. H. I. Deitch and Mr. H. J. McCurrich, immediately following his letter. I would suggest to all those who are champi\&s of catgut that there is no argument about the properties of nylōn, such as has been raging about catgut. Verb. sap.

\section{Nodules at Site of A.P.T. Injection}

Dr. M. F. MCDonnell (Northfleet, Kent) writes: With refererige to the answer given to the query about nodules forming after immunization with A.P.T. (Dec. 22, 1945, p. 908), we find that the following procedure eliminates the lump: (1) insert needle verticatity and deep into upper deltoid muscle; (2) withdraw needle and gently massage the muscle at site of injection.

\section{Correction}

We regret an error on page 3 of the Journal of Jan. 5. "A rapid transfusion of a pint $(473 \mathrm{c.cm}$.) of blood" is wrong. The pint to be transfused should have been an Imperial pint $(568 \mathrm{c.cm}$.) and not a United States Apothecaries' pint (473 c.cm.). 